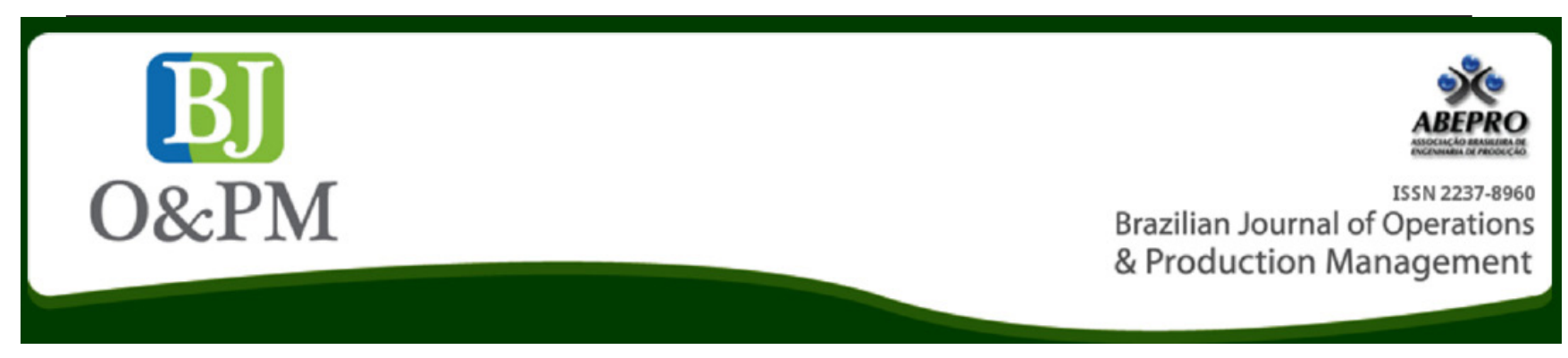

\title{
VALUE STREAM MAPPING AND EARNED VALUE ANALYSIS: A CASE STUDY IN THE PAPER PACKAGING INDUSTRY IN BRAZIL
}

\author{
Gleison Hidalgo Martins ${ }^{a}$; Marcelo Gechele Cleto ${ }^{b}$ \\ a Packaging Industry Professional - Curitiba, PR, Brazil

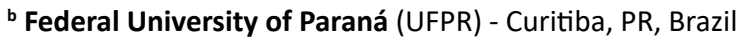

\section{ABSTRACT}

The study approached the application of the Value Stream Mapping and Earned Value analysis methods in a Pinch Bottom with Simple Fold (PBSF) paper bag production line in an industrial packaging enterprise of multiwall paper bags located in Brazil. From the joint application of the mentioned methods, a better diagnosis of the situation was obtained, and the opportunities of eliminating wastes, of operation enhancement, and of a better monitoring of the involved costs appeared, bringing potential production gains and quality to the enterprise. As a contribution of this work, it can be highlighted the presentation and discussion about the complementarity of a Lean Manufacturing tool with a Project Management Methodology.

Key words: Value Stream Mapping, Earned Value Analysis, Paper Bags, Packaging industry, Production Costs 


\section{INTRODUCTION}

The production system management of a company aims to find means to improve its productivity, quality, flexibility, and punctuality. Mapping the value stream allows enterprises to visualize their wastes, which helps them propose enhancements in the process flows. According to Rother et Shook, (2003) , the organizations must think about the flow, instead of implementing discreet production systems or isolated improvement processes. The Value Stream Mapping (VSM) methodology has proved itself efficient by focusing its attention to the flow.

The Earned Value Analysis is pointed out as one of the most important techniques used for controlling projects based on cost, deadlines, and physical progress (Oliveira, 2003). The concept is quite simple: assessment of what was acquired in relation to what was consumed and to what the expenditure planning was. One of the main advantages of the earned value analysis is to calculate the project performance throughout its development, so that it is possible to project deadline estimates, future costs, and corrective and preventive actions beforehand (Vargas, 2011).

The study is justified by the existing gap in the literature related to the VSM and EVA techniques use in the production line of multiwall paper bags package with the application of both methods as a goal. Such application allows the analysis of decision making possibility to be more substantiated based on obtained data in the research, improving, this way, the performance indicators used by the enterprise. The project elaboration will use for the field research the study case technique, which allows the researcher to see in a systemic and meaningful way the real situation of the events. The case studies are the source of richness and extension of the phenomena reality context and require that the researchers face several distinct situations, in which one will obtain more interest variables than the data point out. The fundamental tactics used by researchers to circumvent the variables is to use multiple evidence sources so that the data converge in a triangular form.

\subsection{Packages}

Packages appeared more than 10.000 years ago, being used simply as recipients for drinking or stocking as coconut shells and sea shells in the natural state. The years went by and evolution brought new technologies and allowed man to create new packages by handicraft processes, such as: wooden bowls; natural fiber baskets; animal skin bags; pottery pots and other casings and containers.

Right after the Second World War, the urban life got to know new elements, the industrialization process, the supermarket, and the increase of products consumption. These factors boosted the demand for packages both for the consumer and for the transport companies, causing the raw material price of can packages such as tin and steel to increase, forcing producers to search for new alternatives (Abrae, 2012).

For Abrae the macroeconomics research presented in the $1^{\text {st }}$ semester of 2012, by IBRE (Brazilian Institute of Economics) /FGV (Getúlio Vargas Foundation) disclosed statistics data of the national packaging industry as shown on (Table 1), the revenue of the packaging industry. In spite of the positive results, there was a production decrease in the first semester of 2012 (Abrae, 2012).

\begin{tabular}{ccc}
\multicolumn{3}{c}{ Table 1: Packing Industry's Billing } \\
\hline Year & Sales Revenue & $\begin{array}{c}\text { Gross Product } \\
\text { Amount }\end{array}$ \\
\hline 2008 & 35.4 & 36.4 \\
2009 & 36.7 & 34.9 \\
2010 & 41.9 & 42.8 \\
$2011^{*}$ & 44.7 & 45.6 \\
$2012^{*}$ & 47.0 & 47.9 \\
\hline
\end{tabular}

According to Abrae (2012), the analysis by packaging production sector in the wood, pasteboard, cardboard, paper, glass, plastic, and metal markets withdrew in the first semester of 2012 in comparison to the one in 2011. The main retraction is in the glass market, which production decreased in $10.88 \%$, followed by the wooden $(-8.08 \%)$, metal $(-7.10 \%)$ and plastic $(-3.77 \%)$ markets. The market that stands out is the paper, pasteboard, and cardboard one for being the only one to achieve a positive result with $1.36 \%$ in its production. (Graphic 1) illustrates the participation of each market in the packaging industry.

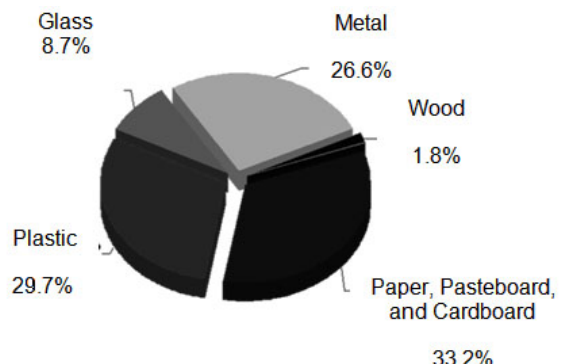

Graphic 1: Physical Production of Packages in Brazil Source: Abrae, 2012

\subsection{Industrial multiwall paper bags}

The multiwall paper bags are originated in Europe in the XVIII century, due to the necessity of increasing the productivity and the speed of salt packaging. Their main functions are: to protect and accommodate the product avoiding contamination, to resist the conditions to which they are subjected, not to mention the space exploitation through all the productive chain, from the manufacturer to the final consumer (Canan, 2011). 
The paper bags are made in several styles and sizes, which vary from 1 to 50 kilos, and are used for the accommodation of several products such as: seeds, flour, chemical products, ores, animal ration, vegetable charcoal, food products, among others. The package models are illustrated by (Figure 1 ), the industrial multiwall bags may be compound of one or more layers and/or combinations with other materials such as: plastic wrap and paper foil (Klabin, 2011).
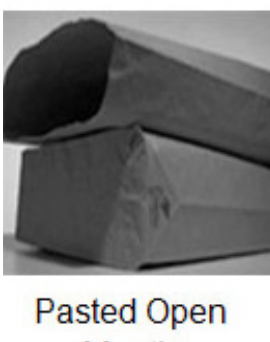

Mouth

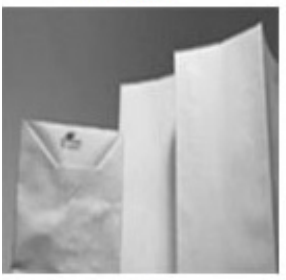

SOS

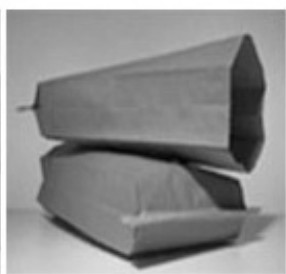

Sewn Open Mouth

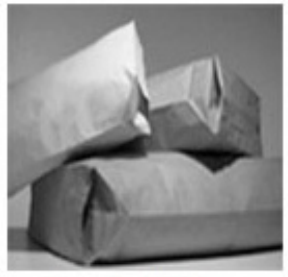

Pasted Valve Sacks

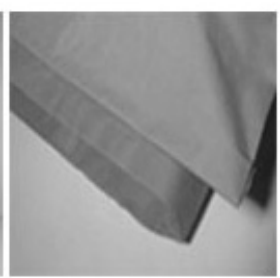

Double Fold

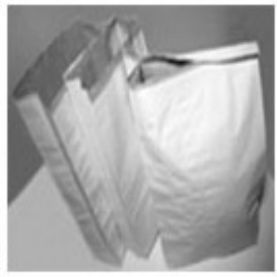

Pinch Bottom
Figure 1: Models of industrial multiwall bags

\subsection{Value stream mapping}

To Rother et Shook (2003), value stream mapping does not mean optimize only the parts in the individual processes, but also to consider the larger picture as a whole. But if one really wants to see them with a systemic vision, it will be necessary to go throughout the whole material transformation process and information to visualize the value stream of a product, this path may cover other productive units as well as other enterprises. It is recommended a lean implementation, since it is a tool that meets the "door-to-door" production flow inside the plant, including the delivery to the costumer's plant, parts arrivals, and purchased materials, where a vision of the future state is projected and it is implemented immediately. The value stream mapping helps to understand the material and the information flow as the product follows the value stream. It is essential to see the flow of the productive systems as a whole. In order to make the results satisfactory, it will be necessary to follow some steps:

1. Select the family of products;

2. Determine the flow manager;

3. Draw the current and future states;

4. Plan and implement.

\subsection{Earned value analysis}

The earned value analysis is a technique used for the controlling of projects in their full cost, deadline, and physical process. It is an important tool that may offer precise and complete diagnoses in any stage of the project helping managers with their decision makings. To Naemi et Salehipour (2010), the earned value analysis measures the performance and the progress of the project, integrating them in the management of the three most important elements: costs, timetable, and scope. To Noori (2008), however, it is a management tool that absorbs some of the cost points of view, such as: the cost by the budgeted programmed work; calculus of the activity distributions based on the budget in relation to the estimated time; complete budget at the end of the project; assessment of the project date by date and verification in the project, the installment value, which should be spent.

According to Vargas (2010), the three basic elements of the terminology for the calculus of the earned value analysis were formed in three classical ways, based on the ANSI/EIA 748 of the American National Standards Institute norm. Once these three parameters (PV, AC, and EV) are determined, the analysis of the results is obtained from the found values in each one of them. (Figure 2), uses a graphic presentation of the three variables of the earned value through the time of a determined period, with an S-shape curve to show the earned value for a project in which its performance is above the one that was planned and is delayed in relation to the work plan.

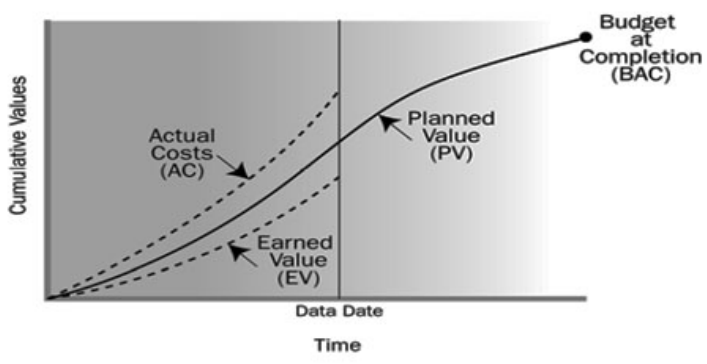

Figure 2: $P V, E V$, and $A C$ through time

It is observed that the definitions for the creation of a project plan consist of four steps according to Vargas (2011) and Oliveira (2003).

1- Work Breakdown Structure;

2- Chronogram Development;

3- Allocations of resources and definitions of control cells;

4- Manufacture of the project baseline (PV).

\section{FIELD RESEARCH}

The choice of the case study method is advantageous for it approaches a systemic and flexible view of the data 
collection and analysis, and for that the used techniques for the research study were: a) Bibliographic research based on materials such as books, theses, dissertations, scientific articles, and websites aiming to clarify concepts and forms; b) Document survey of the project, based on constructive details of the product project, such documents were released by the supervisor; c) In order to elaborate drawings, spreadsheets and graphic of the process according to the proposed model, the MICROSOFT VISION ${ }^{\circledR}$ and OFFICE ${ }^{\circledR}$ software were used; d) data analysis and correlation of the results.

\subsection{The case study}

The selected industry for the empiric research was the Packaging Industry of multiwall bags of Curitiba, Paraná State, Brazil. The enterprise produces several styles of multiwall bags and for this case the selected production line refers to the pinch bottom bags with simple fold (PBSF) family product. The purpose was to collect information from the PBSF production line, and through the theoretical knowledge, accomplish during the practice the value stream mapping and earned value analysis and present the economic viability analysis of the project, which allowed to analyze the earned value of pertinent parts, propose enhancements to the manufacturing process, reduce set up times and also reduce the production line chain cycle time and the scrap rate.

\subsection{The case study outline}

According to Yin (2010), the evidences from case studies may be reached from six sources: documents, archive registries, interviews, direct observations, participant observations, and physical artifacts.

a) Documents: Production Orders (PO), reports of planned costs, reports of the products' real cost used in the research;

b) Archive registries: The enterprise uses a management system called Enterprise Resource Planning (ERP);

c) Interviews: The interviews were performed with responsible members of each section;

d) Direct observations: The direct observations must be done inside the natural environment of the case study;

e) Participant observations: This topic is about a modality in which the observing participant is not only the passive observer, but he/she can also take part of several roles in the case study situations.

f) Physical artifacts: constructive details of the developing package (physical artifact of the multiwall paper bag).

\section{APPLICATION OF THE VSM AND EVA METHODS TO THE CASE STUDY}

In this chapter, the obtained results by the application of both methods to the problem presented in the case study enterprise will be disclosed.

\subsection{Project Diagnosis}

The data collection subsequently enabled the triangulation of various evidence sources. Thus it was possible to develop a data bank creation, in order to analyze the data and obtain results.

\subsection{Data set for the value stream mapping of the current state}

\subsubsection{Production process information}

The production process in the packaging industry for this family involves pre-printing, laminating, tube formation, glue applying at the mouth extremities and at the tube bottom. Each process mentioned above will be processed in some specific equipment and for that production orders are generated for each process.

The estimated time to produce the pilot batch was planned in 10.7 hours, having in mind the equipment setup time and the product processing time in all stages, considering the production historical data and the product complexity, as shown in Board 1, setup historic.

\begin{tabular}{|l|c|c|c|}
\hline \multicolumn{1}{|c|}{ Machine } & Setup & Processing & $\begin{array}{c}\text { Total of } \\
\text { minutes }\end{array}$ \\
\hline Laminate & $50 \mathrm{~min}$ & $50 \mathrm{~min}$ & $100 \mathrm{~min}$ \\
\hline Printer & $50 \mathrm{~min}$ & $50 \mathrm{~min}$ & $100 \mathrm{~min}$ \\
\hline Tuber & $60 \mathrm{~min}$ & $120 \mathrm{~min}$ & $120 \mathrm{~min}$ \\
\hline Bottomer & $60 \mathrm{~min}$ & $200 \mathrm{~min}$ & $260 \mathrm{~min}$ \\
\hline $\begin{array}{l}\text { Total of } \\
\text { minutes }\end{array}$ & & & $640 \mathrm{~min}$ \\
\hline Total of hours & & & $10,7 \mathrm{Hs}$ \\
\hline
\end{tabular}

Customer requirements:

- Pilot batch of 1,600 un of bags;

- Test the package performance;

- Packaging of refractory ores.

Working time of the packaging industry:

- 24 working days per month; 3 shifts of 8 working hours, 40-minute breaks and rosters (6X1). An exception being the bottomer 13 , which works in administrative shifts from 7 a.m. to 5 p.m. 


\section{Production Planning and Control Department:}

- $\quad$ PPC and Sales define the budget and production estimation monthly;

- Sales send sale orders (SO) daily. The PPC runs the MRP (Master Resource Planning) generating the need of materials, tools, input, and raw material.

- The model used to establish the program sequencing in the factory are followed through a report called "production daily map".

\subsubsection{Mapping of the current state}

After collecting the information to elaborate the data set presented on item 4.2.2, the stream mapping of the current state for the production process of the pinch bottom family was developed, as illustrated by (Figure 3), stream mapping of the current state.

\subsection{Data set for the value stream mapping of the future state}

3.3.1. Key points for the value stream mapping of the future state

In order to gather information and stream map the future state the methodology Rother et Shook (2003) will be adopted for the next 8 questions.
Question 1 - What is the Takt time, based on the available working time of the flowing processes below that are closer to the costumer?

The $2 \mathrm{~s}$ takt time is the necessary time that it takes to produce a bag, that is, to meet a 1,600 un production of a pilot batch, it takes approximately 53 minutes.

Question 2 - Would you produce to a supermarket of finished goods from which costumers pull, or direct to shipping?

Due to the high productivity and to the easiness of storage of the finished good, the enterprise directly defined to produce to shipping instead of developing a supermarket, as it is illustrated in (Figure 4), the finished production direct to shipping.
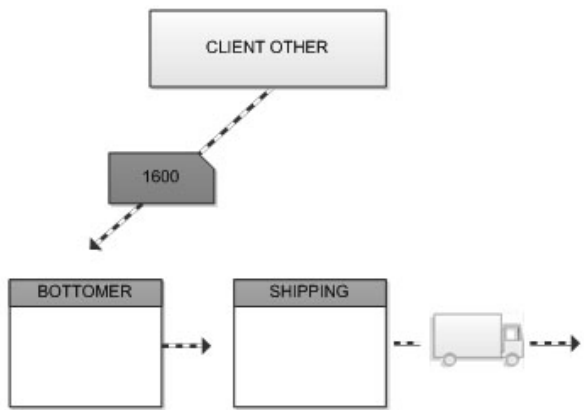

Figure 4: Finished Production direct to shipping

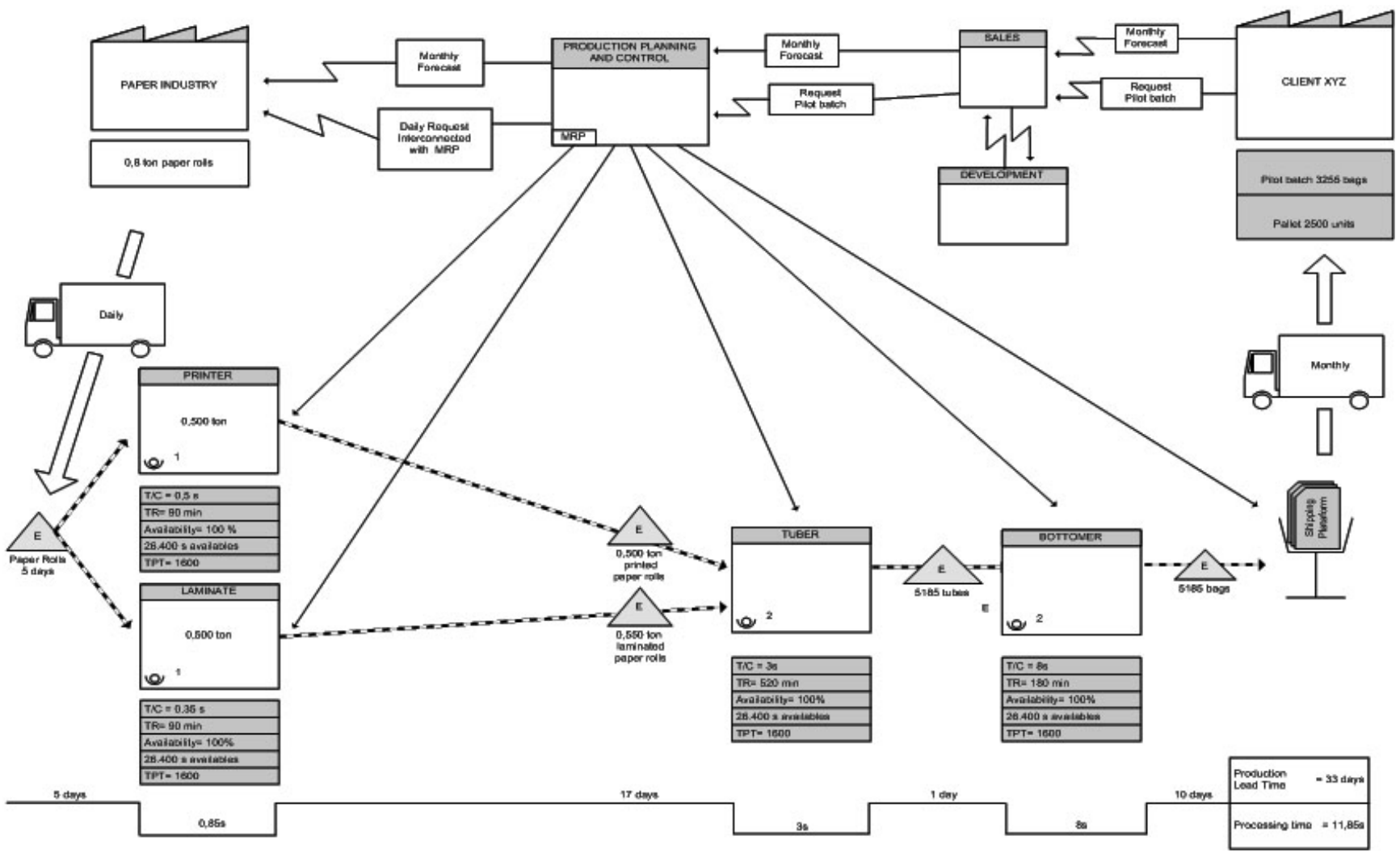

Figure 3: Map of the current stream state 


\section{Question 3-Where can you use the continuous flow?}

In order to reduce the time from $8 \mathrm{~s}$ to $2 \mathrm{~s}$ as it is shown in (Graphic 2), a continuous flow in the manufacturing process must be developed. It is suggested to work with bottomer 13 on three shifts. This way, tuber 10 provides the tubes for the bottomer in a continuous flow, and then directly to shipping. As illustrated in (Figure 5), the produced continuous flow direct to shipping.

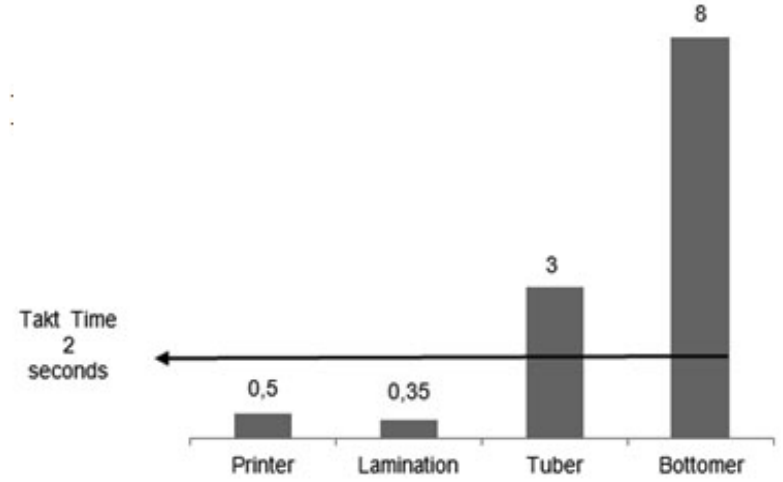

Graphic 2: Current time of the cycles flow direct to shipping

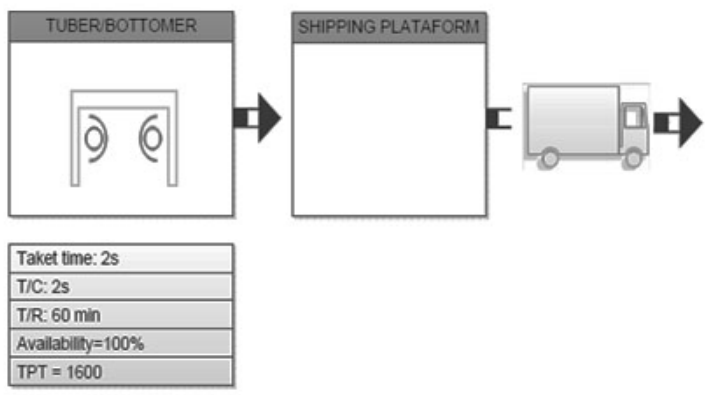

Figure 5: Produced continuous

Question 4 - Where are you going to need to introduce the supermarket pull system in order to control the flowing processes above?

Between the subassembly process and the tuber. After the step of subassembly processes is done, bags are stored again waiting for the tuber order. As the production orders of the bag item are produced, the subassemblies are taken away from the supermarket, as shown in (Figure 6), the supermarket processes are not continuous and the kanbans are developed so they are produced again.

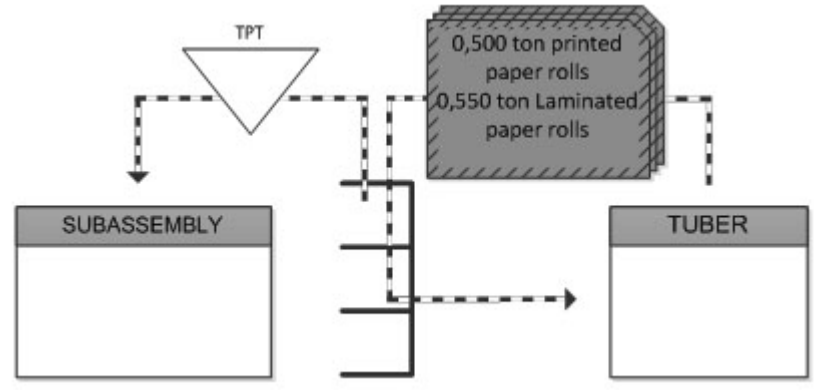

Figure 6: Supermarket of non-continuous process
Question 5-Which is the only production chain point (the pulling process) that the packaging industry chain should program?

The point that the company (PPC) should program would be the bottomer, since all the previous processes need to be in a flow so that a pulling system between the bottomer and the tuber can be planned.

Question 6 - How should the packaging industry level the mix of products in the pulling process?

The production of multiwall pinch bottom bags is made by a specific machine, therefore the mix of products are not significant for this matter.

Question 7 - Which constant working increment should the packaging industry release and take away from the pulling process?

At the moment of boarding, the material controller is responsible for taking away the kabans from the pallets and returning them in the increment in order to route them to the production control section for the emission of new production orders.

Question 8-What are the improvements in the process that are going to be necessary so the value stream of the packaging industry work as it is described in the drawing of the future state?

To make the material and information flow in the packaging industry feasible, the following process enhancements are proposed:

- Flexibility to develop new products; reduce the Lead time; meet the deadlines; reduce the scrap rate; reduce the setup time; improvements.

\subsection{Stream mapping of the future state}

After working in the formulation of the key questions that were elaborated aiming to promote improvements in the production process of the pinch bottom family, a stream map of the future state was developed based on the information gathered from the key questions in item 4.3.1, allowing a clear view of the proposed objective in the flow, as it is illustrated in (Figure 7).

\subsubsection{Analysis of the situation improvement of the case} study

The comparison between the value stream mapping of the current state related to the value stream of the future state, a tendency of positive values for the future indicators of the organization is realized, as it is illustrated on (Board 2), lead time improvements. 


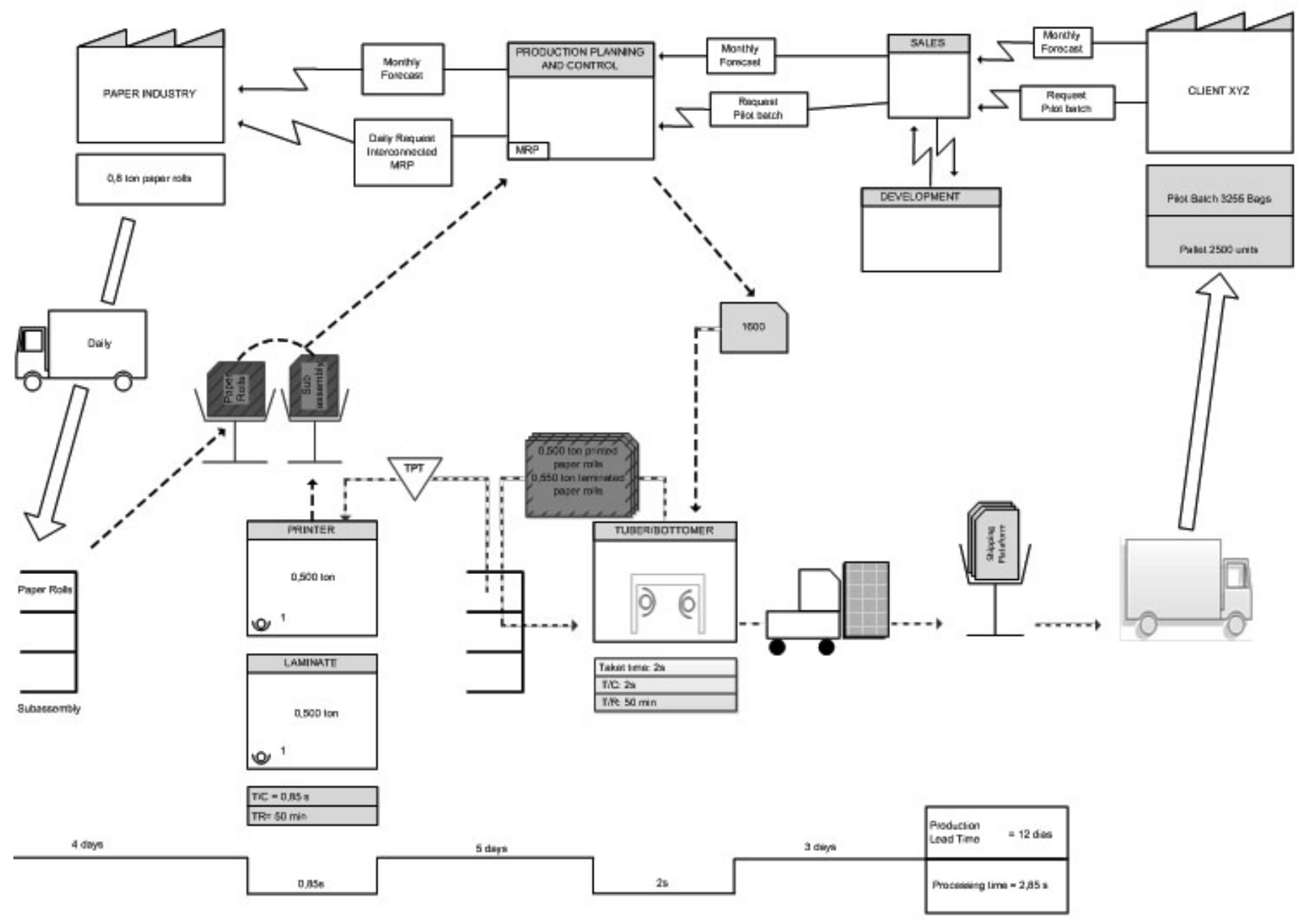

Figure 7: Stream mapping of the future state

Board 2: Lead time improvements

\begin{tabular}{ccccccc}
\hline Time & Rolls of paper & Subassembly & & Finished product & Lead Time & Processing time \\
\hline Before & 5 days & 17 days & 1 day & 10 days & 33 days & 11.85 seconds \\
Pulled continuous flow & 4 days & 5 days & 0 day & 3 days & 12 days & 2.85 seconds \\
\hline
\end{tabular}

- Paper rolls - There will be an 1 day anticipation in the raw material, if the information flow is more efficient with the supplier, for that it will be necessary to follow the monthly schedule as planned (unity of bags);

- Subassembly - First the subassemblies are produced and then they are stored in supermarkets, waiting for the next level of the production process (tuber). This process gets a reduction of 12 days in storage. But it is only possible if the POs of the bag item are started in the bottomer;

- Tuber/Bottomer - as the setup is initialized, it is already possible to start the bottomer setup, waiting for the tube production to finish up the settlement to the closure of the bag bottom, the glue application on the mouth, in the bottomer. Since the flow process is continuous, the waiting time is reduced from 01 day to zero (0);

- Finished Good - the time that it took the product to be shipped to the costumer was also reduced to 3 days, through the production planning sequence;

- Lead time - with the improvement in the information and material stream, it will be possible to perform a planned production so it meets the optimization of resources under the costumer's standpoint. The suggested flow in the elaboration of the future mapping reduces the lead time in 21 days;

- Processing time - In the elaboration of the current map, the product was processed in 3 
stages: subassembly, tubing and bottoming. The processing time was measured in 11.85 seconds. When it comes to the stream mapping of the future, the product will then be processed in 2 stages: subassembly and continuous flow between the tuber and the bottomer. The bottomer reduced the processing time to 2.85 seconds.

\subsection{Earned value analysis}

When considering the development of a new highly complex product of the PBSF family, the earned value analysis was performed in order to measure and assess the project. As soon as the parameters (PV, EV, AC) are determined, analysis results are obtained for each one of them.

\subsubsection{Quantitative example of the earned value analysis}

Following, the project data will be presented, so that the understanding and the content application are eased.

Project: Development of PBSF paper bags

$\checkmark$ Production Order Quantity: 1,600;

$\checkmark \quad$ Planned Budget (BAC): R\$ 3,400.00;

$\checkmark \quad$ Available Time (PAC): 10.7 hours.

\subsubsection{Scope definition of the WBS Project}

The scope is defined through the Work Breakdown Structure (WBS), which objective is to define and control the works to be done, to ensure that the product is produced within the proposed goal. As it is shown in (Table 3), the pinch bottom paper bag WBS project.

After the scope was defined, the cost of each process was estimated, based on the planned cost report and the process time based on the historic production data. The cost is proportioned to the quantity and necessary time to produce.

Each process stage is composed by:

$\checkmark \quad$ Material-Raw material and direct materials;

$\checkmark$ Resources - equipment, knives, and bottomers;

$\checkmark$ Direct costs - depreciation, maintenance, and others.

The Work Breakdown structure (WBS) values are available, as shown on (Table 4), allocation of costs and deadlines.

\subsubsection{Chronogram development}

It was used to define the creation of a chronogram, in a way to identify how the activities are distributed in time, considering delivery deadlines among other tasks. Also to elaborate the planned activity chronogram, the data from item 4.2.1 Process Production Information were used. Now for the chronogram of the carried out activities, they were extracted from the item 4.2.2 Mapping of the current state. Below, (Graphic 3), Gantt Graphic Chronogram, illustrates the planned time versus the realized time, after the activities were concluded.

Table 3: Pinch bottom bag project

|--------1.1 Subassembly process

|--------------1.1.1. Printing Stage

|----------------1.1.2. Laminating Stage

|-------------------1.2 Tuber process

|----------1.2.1. Tube Formation

|--------------------1.2 Bottomer Process

|----------------1.3.1. Tube Closing

|-------------------1.2 Packaging Process

|--1.4.1. Package

Table 4: WBS - Allocation of cots and deadlines

\begin{tabular}{|c|c|c|}
\hline Pinch Bottom Bag Project & Cost (\$) & Duration \\
\hline \multicolumn{3}{|l|}{ |---------------1.1 Subassembly Process } \\
\hline |---1.1.1. Printing Stage & 307.00 & 1.66 \\
\hline |------------1.1.2. Laminating Stage & 203.80 & 1.66 \\
\hline \multicolumn{3}{|l|}{ |------------1.2 Tuber Process } \\
\hline |-----------1.2.1. Tube Formation & 1230.512 & 3.00 \\
\hline \multicolumn{3}{|l|}{ |---------------1.2 Bottomer Process } \\
\hline |-----------------1.3.1. Tube Closing & 1577.584 & 4.17 \\
\hline \multicolumn{3}{|l|}{ |------------------1.2 Packaging Process } \\
\hline |-----------------1.4.1. Package & 82.06 & 0.16 \\
\hline Total & 3400.96 & 10.7 \\
\hline
\end{tabular}




\subsubsection{Allocation of resources and definitions of cells}

To determine the cost of each activities, among them: planned cost, realized cost, and earned value, the values of each processes were identified as illustrated on (Graphic 4), auxiliary table of cost distributions.

\subsubsection{Manufacturing baseline of the project}

With the scope defined, it is only necessary to follow the progress and assess the performance of the project in the Planned Value (PV) baseline, where all the information from the project is outlined, such as: chronogram, cost, activities, control, etc. Below, (Graphic 5) helps visualize the budget baseline of the planned value.

Because it is a short-term project, the time was counted in hours and then it was chosen to measure the data after the project was concluded. This way the manager, through incurred costs and the physical progress of the project performed a systemic analysis in order to search for the AC and the EV curves.

It is noticed that the manager had planned a 10.7-hour time to conclude the project, projecting that the cost value would be of $R \$ 3,400.00$ PV. However, up to the reference

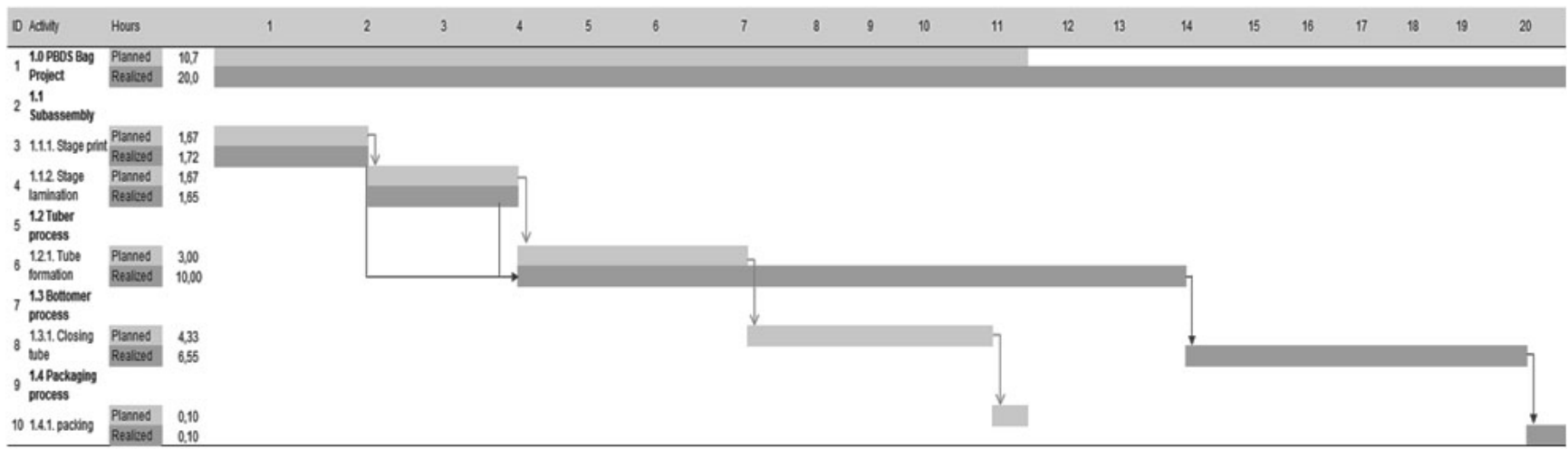

Graphic 3: Gantt graphic chronogram

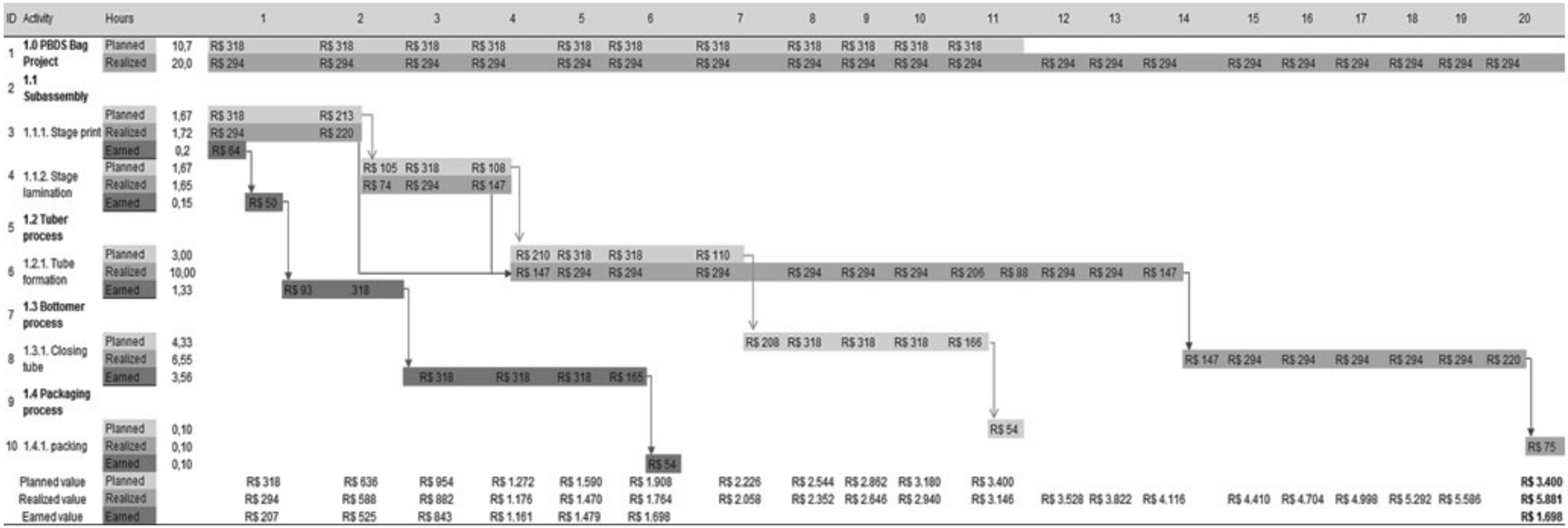

Graphic 4: Cost distribution

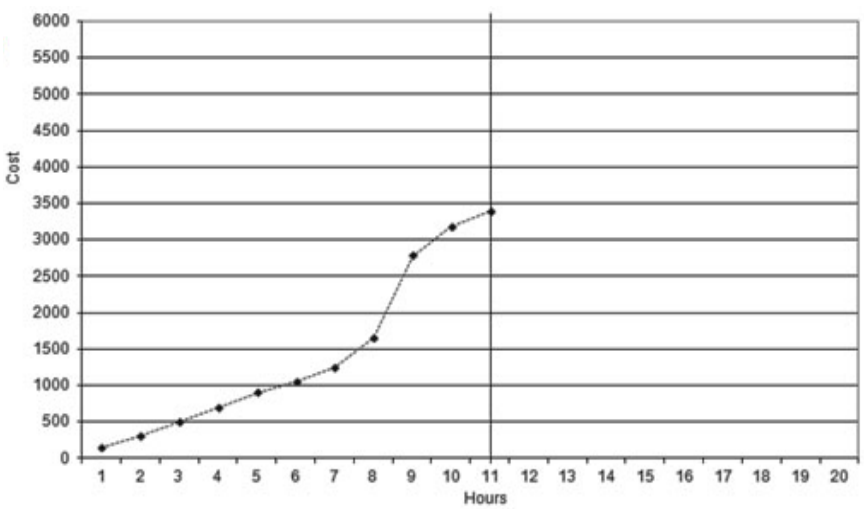

Graphic 5: Budget baseline of the PV

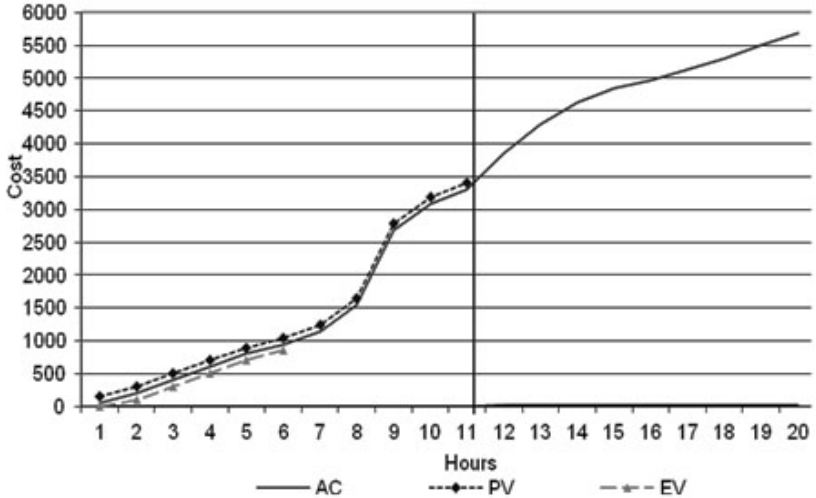

Graphic 6: Earned Value Analysis 
date, $R \$ 3,146.00$ had been spent, and the earned value had been of only $\mathrm{R} \$ 1,698.00$. Below (Graphic 6 ) is shown to outline the project analysis through the lines.

As presented on chapter 2.4 Earned Value Analysis, the cost terminologies, deadline and performance rate were calculated up to the reference date.

- $\quad \mathrm{CV}=\mathrm{EV}-\mathrm{AC}$

$\mathrm{CV}=\mathrm{R} \$ 1,698-\mathrm{R} \$ 3,146=(-\mathrm{R} \$ 1,448) ;$

- $\quad \mathrm{SV}=\mathrm{EV}-\mathrm{PV}$

$S V=R \$ 1,698-R \$ 3,400=(-R \$ 1,702) ;$

- $\quad \mathrm{TV}=$ (Graphically obtained)

TV = 9.3 hours;

- $\quad \mathrm{CPI}=\mathrm{EV} / \mathrm{AC}$

$\mathrm{CPI}=\mathrm{R} \$ 1,698 / \mathrm{R} \$ 3,146=0.54$;

- $\quad S P I=E V-P V$

$S V=R \$ 1,698 / R \$ 3,400=0.50$.

It is observed through the calculated data up to the reference date, that the project presented lower estimated costs, and delays on the chronogram and conclusion of the project. It was measured that the work time conversion and the invested value were below the expectations.

\section{FINAL CONSIDERATIONS}

\subsection{Research considerations}

The initial research by using two methodologies about value stream mapping and earned value analysis, in the production line of pinch bottom with simple fold (PBSF) paper bag family, aimed to help the organization achieve systematic improvements, by eliminating not only waste, but also its causes. This study allows the enterprise to visualize in its procedures the waste sources, as well as the performance of the earned value analysis of the product, which may contribute to the application of new improvements. Besides the value stream mapping of the current state, a stream value of the future state was developed, and the economic feasibility of the project was analyzed.

To present the final considerations about the obtained results in the research, it will be necessary to revise the general objectives and confront them with the results of the analyses. It will also be presented some considerations about the methodology and suggestions for future works.

The development of the data set to construct the current map has organized the stream details in each pertinent process of the production line of the PBSF family, thus the development for the map construction with future applications both on the flow and on the actions was elaborated, which resulted in analyzing points for the achievement of the proposed general objective.

\subsection{Methodology considerations}

The used methodology was of great importance for the case study performance, and it clearly and succinctly showed how the research development must be carried out. The joining of two authors Rother et Shook (2003) (VSM) et Vargas (2011) (EVA), created an essential tool for the elaboration and application of the methods in collecting and processing the resulting information.

Through the application of these two methodologies (VSM) and (EVA), it was possible to map all the process in question, and to collect information for the data set of the value stream and later of the information processing - which was only possible through the data from the value stream mapping - that was performed through the earned value analysis, obtaining, as a result, the project feasibility.

\subsection{Considerations about the results of the performed analyses}

With the application of the two methodologies, the value stream mapping and the earned value analysis, it was possible to visualize all the process of the PBSF family production line, such as: value stream, planned value, real cost, cost variations, chronogram, and performance rates according to the concepts and terminologies presented in the research. For the case study, the joining of both tools was efficient, since it has mapped out all the production line flow when it collected the information flow and then processed it, through the value analysis, which reached, as a result, a very high lead time, and in order to reduce it, the organization will need to enhance the systems (the flow, equipment and workforce), so it has an economically potential and profitable product for the enterprise.

The intention is to propose to the enterprise the use of both methodologies, which is fundamental to obtain a wider knowledge of the value stream in the production line, and in the future, deploy it in other lines, i.e. the managers would have in their own hands a helping tool when making decisions about project control of costs, deadlines and physical progresses as a whole.

\section{REFERENCES}

Abrae (2012). Associação Brasileira de Embalagens [Brazilian Association of Packages]. Available at < http:// www.abre.org.br> Retrieved in: May 1, (In Portuguese).

Canan C (2011). Agregando valor ao produto. [Adding value to the product]. Available at< http://cabanhacanan. com.br/area_publica/controles/ScriptPublico. php?cmd=verNoticia\&codigo=68> Retrieved in: August 20. (In Portuguese) 
Hidalgo Martins, G. et al (2007). Relatório de gestão. TCC (Graduação em Administração de Empresas) [ Management reporte. TCC (Graduate in Business Administration)] p.71, 144. Paranaense Society of Education and Informatics. Curitiba, p.71; 144.

Klabin (2011). Produtos: sacos industriais. [Klabin Products : industrial bags] Available at< http://www.klabin. com.br/pt-br/produtos/linha.aspx?idLinha=7> Retrieved in: May 1. (In Portuguese)

Martins P. G.; Laugeni F. P (2005). Administração da produção [Management of production]. 2a ed. São Paulo: Saraiva, p.88.

Naeni M; Salehipour A (2010). Evaluating fuzzy earned value indices and estimates by applying alpha cuts. Expert Systems with Applications 38 (2011) 8193-8198 p. 81938194.

Noori, S. et al (2008). Designing a control mechanism for production planning problems by means of earned value analysis. Journal of applied science 8(18): 3221-3227.

Oliveira, R. C. F (2003). Gerenciamento de projetos e a apliacação da Análise de valor agregado em grandes projetos [Management of projects and the application of the Earned Value Analysis in large projects.] Dissertation (Master in Naval and Oceanic Engineering) p.48; 59. Polytechnic School of the University of São Paulo. São Paulo. (In Portuguese)

Rother, M; Shook, J (2003). Aprendendo a enxergar Mapeando o Fluxo de Valor para Agregar Valor e Eliminar o Desperdício [Learning to see - Mapping the Value Stream in order to Earn Value and Eliminate the Waste]. São Paulo: Lean Institute Brazil. (In Portuguese)

Tubino, D.F (1999). Sistemas de produção: a produtividade no chão de fábrica [Production systems: productivity on the manufactory floor]. Porto Alegre: Bookman, p. 111-112.

Vargas R. V (2011). Análise do valor agregado em projetos. Revolucionando o gerenciamento de prazos e custos [Earned Value Analysis in projects. Revolutionizing the management of deadlines and costs]. 5th ed. Rio de Janeiro: Basport. (In Portuguese)

Yin, R. K (2010). Estudo de caso: planejamento e métodos [Case Study: planning and methods]. 4th ed. Porto Alegre: Bookman, p 20-25. (In Portuguese)

\section{GLOSSARY OF TERMS:}

Takt time : To Rother and Shook (2003), Takt time is the frequency in which a product must be produced based on the sales' rhythm to meet the costumers' demand;

Cycle time (T/C) : According to Rother and Shook (2003), the cycle time is given by the time lapse between the end and the beginning of a process, it is defined by two elements: time unit of each machine processing, and the number of workers by cell ;

Value Added Time (VAT): Value Added Time is the perception that the costumer has of a product or service considering the competition-related cost/benefit Canan (2011). It is the time of the transformation of a product in a way which the costumer is willing to pay, Rother and Shook (2003);

Lead Time (L/T) : To Tubino (1999) and Hidalgo Martins et al (2007), the lead time is a time measure, related to the productive system flexibility to answer the costumer's order;

Changing time: To Martins and Laugeni (2005), the changing time is the work performed to prepare the equipment for production;

PV (Planned Value): They are authorized values for the performance of an activity. It comes from the baseline cost divided into levels and accumulated until the status date, or the date of the current project, Vargas (2011);

AC (Actual Cost): It presents the total costs derived and registered in the work performance, done by a resource or activity until the actual date of the project, derived from the financial data, Vargas (2011);

EV (Earned Value): It is the value of the concluded work in terms of approved budget and aggregated to the analytical structure of the project, budget installment which should be spent, considering the realized work until the actual status and the baseline costs for the activity, attribution, or resources, Vargas (2011);

CV (Cost Variance): It is the difference between the predicted cost to reach the actual conclusion status level of the Earned Value (EV) and the Actual Cost (AC) until the status date, Vargas (2011);

SV (Scheduled Variance): It is the difference in terms of Earned Value (EV) and Planned Value (PV) costs. If the SV is positive, the project will be put forward; if it is negative, the project will be delayed, Vargas (2011);

TV (Time Variance): It is the difference between the time terms, between the one predicted by the project (PV) and the realized one $(E V)$. This difference between the status date and the PV date, represents the delay and/or the advancement, Vargas (2011);

SPI (Schedule Performance Index): It is the conversion rate between the Earned Value (EV) and the Planned Value (PV) , Vargas (2011);

CPI (Cost Performance Index): the CPI Index is the conversion rate between the earned value (EV) and the actual cost $(A C)$, this index shows the real value consumed by the project and the earned values in the same time period, Vargas (2011). 